Educational Guidance and Counseling Development Journal p-ISSN: 2615-3661 | e-ISSN: 2615-8358

Vol. 1, No. 1, April 2018, 1 - 5

\title{
Relationships between Attachment Style and Depression Level among Undergraduate Students
}

\author{
Amalia Madihie ${ }^{1}$, Azlan Bin Andika², Fiona anak Kunang ${ }^{3}$, Diyana Syazana Binti Omar ${ }^{4}$, \\ Debra Bte Simar ${ }^{5}$, Chan Wei Sian ${ }^{6}$ \\ 1,2,3,4,5,6, Counselling Programme, Universiti Malaysia Sarawak, Malaysia \\ Email: mamalia@,unimas.my
}

\begin{abstract}
This study was conducted to identify the depression level of university student in Sarawak based on four types of attachment style. Therefore, undergraduate (UG) students from a university as sample for this study. Three hundred and sixty UG students were randomly chosen to be the respondents for this study since the population was 2200 UG students in a faculty. Questionnaire was employed in the study to collect required information or data. Questionnaire consists of three parts which are Section A: Demographic of respondents, Section B: Experience in Close Relationship Test (ECR), and Section C: Centre for Epidemiologic Studies Depression Scale (CES-D). ECR applied to determine the attachment style of students and CES-D used to identify the level of depression of students. As for the data analysis, Pearson Correlation Analysis was carried out. Finding showed there was significant relationship between attachment style and depression level among the UG students where the $p$-value (0.000) is smaller than alpha value (0.005). Expertise could utilize the findings of study to develop some suitable module of intervention to help client suffer from depression due to relationship problem.
\end{abstract}

Keywords: Depression, Attachment Styles, Undergraduate Students, University, Malaysia

\section{INTRODUCTION}

Connection style and psychological wellness has been a focal theme for studies since the start of connection hypothesis being presented. There has dependably been an interest in knowing a person's connection style and how it will influence the person's mental prosperity. An everincreasing number of studies have demonstrated solid confirmation that the sort of connection style assumes a part in the inclination of a man having melancholy. As indicated by general outcomes, people with unfortunate connection styles are more inclined to create dejection. With the ascent of numerous more confirmation relating connection style to melancholy, more introduction should be possible towards guardians and parental figures to maintain a strategic distance from the improvement of undesirable connection styles.

The theory of attachment styles is first introduced by Mary Ainsworth. This theory was developed from an experiment called 'Strange Situation Classification' or SSC. The experiment involved the infants to be in a room and the infants will experience multiple situations like the mother being with the infant and then leave him, the mother came back but with a stranger and then leave the stranger with the infant and many more.

From the observation of the infants' behavior, three main attachment styles were introduced by Ainsworth namely the secure (Type B), insecure avoidant (Type A) and insecure ambivalent/resistance (Type C). The fourth attachment style was then identified which is called disorganized (Main, \& Solomon as cited by McLeod, 2014). Infants with secure attachment typically have attachment figure that is available and sensitive to their needs. While infants with 
type A attachment usually have attachment figure that are "unavailable during emotional distress" (McLeod, 2014). Infants with type $C$ attachment resulted from inconsistent availability to cater their needs by the attachment figure. From this on, a lot of new concepts and knowledge about attachment styles have been added throughout the years. The SSC experiment shows the need of parents and caregivers to be more sensitive with the needs of their children. The misconception that a child would not remember or know what happened should not be continued. Psychoanalyst John Bowlby further elaborated on this attachment theory that attachment to maternal figure is so important that without it, severe implications can occur to the child. Examples of the implications are delinquency, reduced intelligence, increased aggression, depression and affectionless psychopathy (McLeod, 2007).

According to World Health Organization (WHO) (2017), depression is a mental disorder that is suffered by more than 300 million people around the world. Furthermore, statistics show that in many countries less than $10 \%$ of people with depression receive treatments. This is contributed by many factors; "lack of resources, lack of trained health care providers" and the social stigma of mental health in general (WHO, 2017). There are three categories of depression; mild, moderate and severe. The symptoms of depression are; "difficulty concentrating, remembering details and many more". Severe depression may lead to suicide. WHO also reported that the second leading cause of death of people aged 15 to 29 is suicide. This unsettling fact is one of the reason for more studies need to be done so that depression can be detected early and more lives can be saved from succumbing to suicide. In 2012, World Health Organization (WHO) statistics stated that the second largest cause of death among youths age 15-29 globally is in fact suicide (Lakshiny, 2015). In 2016, Malaysia is shocked by the news that a Malaysian student committed suicide in Taiwan. This student went unnoticed in having depression (Cheng, 2016).

In a study conducted by Erozkan (2011), attachment styles and depression as well as loneliness have significant correlation. According to attachment theory, those with secure attachment in childhood will base their subsequent relationships in the secure relationship that they had. Furthermore, individuals with secure relationships have more resiliency towards stress, self-reliance and confidence (Bowlby as cited by Erozkan, 2011). The opposite can be said about those with insecure attachment. Individuals with insecure attachment are more vulnerable to depression and loneliness (Erozkan, 2011).

Notwithstanding the examination objective, we need to ingrain the respondents with the learning about themselves and spread the mindfulness about sadness. In addition, we need to have the capacity to recognize if there are any university students who are in their understudies that may have unhappiness and ready to find a way to intercede and help them.

\section{METHODOLOGY}

\section{Population/Samples}

The targeted samples were from a faculty which consisted of three offerred programmes. A total of 360 students are targeted to be the respondents of this study. This is based Krejcie and Morgan table on FCSHD population which is 1944. The respondents were randomly selected students of any program and year of study.

\section{Method}

Researchers used a survey method to answer the objectives and hypotheses of the research. In this research there were three sections in questionnaire: Section A, Section B, and Section C. Section A consisted of demographic information such as gender, race, religion, faculty, and status. Section B was the Experience in Close Relationship test (ECR) by Brennan and Shaver. Meanwhile, section C is Centre for Epidemiologic Studies Depression Scale (CES-D). 
The ECR inventory has 36 items that measures the respondents on two subscales; avoidant and anxiety. The ECR has shown to be highly reliable $(\alpha>.80)$ in terms of its composite scores for anxiety and avoidant (Fraley, Heffernan \&Vicary, 2011).

The CES-D was used to assess the depression level in respondents. CES-D has shown to be suitable to be used to adolescents and its internal scale consistency coefficient was 0.74 in general (Tatar et al., 2013).

\section{Analysis}

The data analysis for our research hypothesis might be using Pearson Correlation in SPSS 21. Pearson Correlation is suitable used to determine whether there is a linear relationship between a pair of variables (attachment style and level of depression) in research hypotheses.

Besides, Chi-Square in SPSS was used to analysis the frequency and percentage of the depression level which are mild, moderate, and severe based on four types of attachment style.

\section{FINDING \& DISCUSSIONS}

Researchers focused more on the result of the data that had been collected from 360 respondents. After conducted the SPSS whereby the data were analyses by using Pearson Correlation the result were discussed for each type of attachment style. In addition, researchers also using Chi-Square to check the frequency result for depression level. Three level of depression which are mild, moderate, and severe. Based on Chi-Square, there were significance difference among these three levels of depression and attachment style.

To sum up, it was found that null hypothesis was rejected for dismissing attachment style, secure attachment style, and avoidant attachment style. Value $a=0.05$. These three attachment styles having $p$ value less than a value $(p<a)$ therefore, there is significant relationship between dismissing attachment style, secure attachment style, and avoidant attachment style with the level of depression. However, we reject the alternative hypothesis for fearful attachment style. This attachment style having $p$ value more than a value $(p>a)$ therefore, there is no significant relationship between fearful attachment style and depression level.

After led the SPSS test in this manner, the researchers could state that secure is corresponded with level of depression. Individuals who are safely joined for the most part turn out to be obviously disturbed when their guardians leave and are upbeat when their folks return. Whenever unnerved, these kids will look for solace from the parent or guardian. Secure attachment is characterized by the infant having the caregiver or attachment figure as the base for the exploration (Psych101, 2010). Grown-ups with secure attachment are more flexible in relationships as well as have higher resiliency towards stress and are more independent and have higher self - confidence (Bowlby as cited by Erozkan, 2011).

After led the SPSS test in this manner we could state that avoidant is corresponded with level of depression. When one has avoidant attachment style it is a bit much that he or she has depression. Since avoidant individuals in this circumstance seek less closeness with their accomplices. From one perspective, the connection between attachment styles and longing for less closeness is unsurprising. For example, relational troubles like relational dismissal, lacking social support, and conjugal issue. Hence, in each individualthat has avoidant connection there will be most likely face sadness also whether mild, moderate or severe it is rely on upon the individual element themselves. Furthermore, Individual with avoidant attachment tend to be heavily selfreliant and seldom disclosure themselves to partners or rely on them (Devito, 2014). According to Whiffen (2005), couple who are avoidant attachment usually insensitive toward partners' emotional needs. It can be support by research of Burnette et al. (2009), individual with avoidant attachment lack of empathy and feel that other people is unworthy for their caring. 
After conducted the SPSS test therefore we could say that dismissing is correlated with level of depression. When one has dismissing attachment style it is not necessary that he or she has depression. Because dismissing people tend to feel comfortable over themselves and what they have in hand. They prefer to count on themselves more than count on other people. What important to them is that they are satisfied with themselves. They rather work alone than working in group. They not trust anyone and always withdraw from relationship and they hate the fact that people are depending on them. Therefore, in every people that has dismissing attachment there will be most probably face depression as well whether mild, moderate or severe it is depend on the individual factor themselves. Individual with dismissing attachment are characterized by behaving in contradictory manners (Psych101, 2010). Furthermore, the behaviours of adults with this kind of attachment style usually place little value or importance on having relationship with others (Djossa, 2014). Also, according to Djossa (2014), dismissing style individuals suppress their desires for intimate attachments.

Individual with fearful attachment is hypersensitive to their availability of partners. They need a lot of emotional reassurance from partners in order to feel secure in their intimacy relationship. Reassurance from partner could help them feel their spouse is supportive and respond to their emotional needs. (Devito, 2014) Wei et al. (2004) found that people with fearful attachment might develop maladaptive pattern of perfectionism. They tend to use their perfectionism as coping mechanism for unfulfilled interpersonal needs. However, Scharfe (2007) found that pregnant woman with fearful attachment had higher level of depression during early postpartum. Therefore, they would isolate themselves and withdraw from social interaction. Hence, we could conclude that it is not necessary that when one has fearful attachment at the same time has depression as well.

\section{IMPLICATIONS}

There are few significant implications that researcher enlisted while conducting the study of attachment style with level of depression among the undergraduate students. Firstly, when researchers know the relationship of depression and types of attachment that a client have therefore they could develop some suitable modules of intervention. This is important so that client and counsellor are not harming each other. Client would not develop withdrawal condition due to unfit to the module of intervention. With this study will help the profession to be more and more effectives. For example, if the client identified has dismissing attachment style then counsellor could arrange some modules, inventories and approaches that fit with the condition of the client respective with their level of depression.

Secondly, the study would also help as an added value in the learning of counselling. This would help the industry to be fill by a competent counsellor that empower with knowledge about relationship between attachment style and level of depression. Previous study had shown that there is significant relationship between insecure attachment style with depression. Individual with insecure attachment style such as fearful, dismissing, or occupied is more prone to depression compare with people with secure attachment. (Erozkan, 2011)

Thirdly, this study also significant to the ministry. Ministry could conduct a big-scale of survey based on this study to collect the current state of mental health at university. This effort is very crucial in identifying the level and state of mental health of students. Specific interventions may propose at university level to assist the students especially at the undergraduate level in preparing them mentally before entering the industry world. As such preparation, the country will benefit the well-being in individuals who work and definitely will boost up the country's economic through productivity. 


\section{CONCLUSION}

In conclusion, the higher the percentage of secure attachment the lower the depression level which means lower suicidal ideation or attempt among the university students. Awareness towards secure attachment styles would lead to lower depression level. The study hopes to be one of the reference as counsellor conducting session in the future with involvement of client with depression issue. Further study should be continued so that a strong and concrete finding could be obtain and develop as a proper intervention. This is crucial to the field since that suicidal cases have become prevalent cases these day and it is a serious matter to be handle by the counsellor in the field. Therefore, with the study would help in reducing such cases and some day would eliminate it once and for all.

\section{REFERENCES}

Cheng, N. (2016, April 9). Depression may have led to Malaysian student's suicide. The Star Online. Retrieved from www.thestar,com.my/news/nation/2016/04/09/depression-mayhave-led-to-malaysian-students-suicide

Devito, C. C. (2014). The Link between Insecure Attachment and Depression: Two Potential Pathways (Unpublished master thesis). University of Massachusetts-Amherst, United States

Djossa, E. (March, 2014). Understanding the needs of the avoidant/dismissive attachment style. Retrieved from the-love-compass.com/2014/03/01/understanding-the-needs-of-theavoidantdismissive-attaachment-style/

Erozkan, A. (2011). The attachment styles bases of loneliness and depression. International Journal of Psychology and Counselling, 3(9), 186-193.

Lakshiny. (2015, September 7). Suicide is the $2^{\text {nd }}$ leading cause of death among youth - A closer look at the situation in Malaysia. Malaysian Digest. Retrieved fromwww.malaysiandigest.com/features/568013-suicide-is-the-2nd-leading-cause-ofdeath-among-youth-a-closer-look-at-the-situation-in-malaysia.html

McLeod, S. A. (2014). Mary Ainsworth. Retrieved from www.simplypsychology.org/mary ainsworth.html

McLeod, S. A. (2007). Bowlby's Attachment Theory. Retrieved from www.simplypsychology.org/bowlby.html

Psych101. (2010). Attachment theory. Retrieved from https://www.saylor.org > site > 2010/11

Tatar, A., Kayiran, S. M., Saltukoglu, G., Ozkut, E. S. Z., \& Emeksiz, M. (2013). Analysis of the center of epidemiologic studies depression scale (CES-D) in children and adolescents from the perspective of the item response theory. Bulletin of Clinical Psychopharmacology, 23(3), 242-253.

World Health Organization. (2017). Depression. Retrieved from www.who.int/mediacentre/factsheets/fs369/en/ 